The few cases seen by one of us (G.A.R.) were all Indians, and they took a long time to respond to vitamin- $B_{12}$ injections, vitamin-B complex injections, pantothenic acid, and diet. Unfortunately, the composition of the vitamin-B complex injections which had been used more than 10 years ago could not be determined. We therefore tried the effect of pure parenteral riboflavine in this case.

This was a classical case of a pure burning-feet syndrome. The patient had severe burning pains in the feet, worse at night, and apart from brisk knee jerks there was a significant absence of positive physical signs. She showed no clinical evidence of riboflavine deficiency. Though she did not suffer from diarrhoea, the low xylose excretion, the flat glucose tolerance curve, and the low vitamin-A-absorption test showed that she did in fact have malabsorption. Her defective diet and repeated pregnancies no doubt aggravated the situation.

This patient had very low serum folic acid levels, only 1.4 ng. $/ \mathrm{ml}$. Folate deficiency can give rise to various neurological disturbances (Brain, 1969), but it could not have been responsible for this patient's burning-feet syndrome, since this cleared up with parenteral riboflavine alone. Folic acid is absorbed from the jejunum and so is riboflavine (Selye, 1943). Riboflavine possesses vitamin activity only after it has been phosphorylated, a process thought to occur in the intestines. Riboflavine is not readily phosphorylated or absorbed in patients with gastrointestinal disease and is utilized only in such patients if it is injected (Bicknell and Prescott, 1953).

The burning-feet syndrome has long been recognized to be a result of vitamin deficiency, though the responsible factor has been controversial. Earlier observations noted the frequent association of the burning-feet syndrome with signs of riboflavine deficiency-corneal vascularization, angular stomatitis, glossitis, and scrotal dermatitis (Landor and Pallister, 1935; Stannus, 1944; Peraita, 1946). Hence it was thought that riboflavine was the deficient factor, and indeed the syndrome improved after treatment with substances containing riboflavine, such as yeast and Marmite. At that time a pure preparation of riboflavine was not available. Nevertheless, other workers reported little success in treatment of the burning-feet syndrome with riboflavine (Gopalan, 1946; Cruickshank, 1952). Cruickshank (1946), writing about his experience of 500 cases of the syndrome seen in prisoners-of-war in Singapore, thought the syndrome was due to deficiency of nicotinic acid, "perhaps in conjunction with riboflavine deficiency," after having found a good response in $68.8 \%$ of cases treated with intravenous diethylamide of nicotinic acid. During the later part of the war, however, there was no fresh outbreak of the burning-feet syndrome when the dietary content of nicotinic acid again fell to low levels. Pantothenic acid was later incriminated when Gopalan (1946) cured 53 cases by means of parenteral calcium pantothenate after having failed with thiamine, riboflavine, and nicotinic acid. Gopalan's results, however, could not be substantiated by Bibile et al. (1957) when they carried out a controlled therapeutic trial with pantothenol, the alcohol derivative of pantothenic acid.

The response of the present patient to intramuscular riboflavine therapy was dramatic. She obtained great relief of pain after three days and was completely cured after six days. During this period she was not given any other vitamin therapy, and liver was excluded from the ordinary hospital diet. In any case she suffered from malabsorption. While we cannot deny that the cure in this single case might have been a placebo response, it certainly draws attention back to the early hypotheses that riboflavine deficiency is the cause of the burning-feet syndrome.

We wish to thank Professor M. J. Colbourne, of the University Department of Social Medicine and Public Health, for carrying out the dietary investigations, and also Dr. W. P. Fung, of the Department of Clinical Medicine, for doing the jejunal biopsy.

\section{REFERENCES}

Bibile, S. W., Lionel, N. D. W., Dunuwille, R., and Perera, G. (1957). British fournal of Nutrition, 11, 434

Bicknell, F., and Prescott, F. (1953). The Vitamins in Medicine, 3rd ed.,

Brain, M. C. (1969). In Recent Advances in Neurology and Neuropsychiatry, 8th ed., edited by Lord Brain and M. Wilkinson. London, Churchill.

Cooke, W. T., and Smith, W. T. (1966). Brain, 89, 683.

Cruickshank, E. K. (1946). Lancet, 2, 369.

Cruickshank, E. K. (1952). Vitamins and Hormones, 10, 1

Fung, W. P., and Khoo, O. T. (1969). Singapore Medical fournal, 10, 198.

Gopalan, C. (1946). Indian Medical Gazette, 81, 22.

Landor, J. V., and Pallister, R. A. (1935). Transactions of the Royal Society of Tropical Medicine and Hygiene, 29, 121

Peraita, M. (1943). Fournal of Nutrition, 25, 137.

Smith, D. A., and Woodruff, M. F. A. (1951). Medical Research Council. Special Report Series, No. 274.

Stannus, H. S. (1912). Transactions of the Society of Tropical Medicine and Hygiene, 5, 112.

Stannus, H. S. (1944). British Medical fournal, 2, 103.

\title{
Preliminary Communications
}

\section{Absence of Antidiuresis during Administration of Prostaglandin $\mathbf{F}_{2} \alpha$}

British Medical fournal, 1970, 2, 152-154

Qummary: Water diuresis was induced in six patients $\checkmark$ in mid-pregnancy. Three were then given oxytocin and the remainder prostaglandin $\mathbf{F}_{2} \alpha \quad\left(\mathbf{P G} \mathbf{F}_{2} \alpha\right)$, both drugs being infused intravenously in doses used to induce labour at term. Pronounced antidiuresis occurred with oxytocin, whereas $\mathbf{P G F}_{2} \alpha$ showed no such effect. The probable absence of any risk of water intoxication when using $\mathbf{P G F}_{2} \alpha$ in inducing labour may be of particular value when maternal pre-eclampsia or renal disease is present.

\section{INTRODUCTION}

Intravenous infusions of dilute solutions of oxytocin have been widely used for induction of labour. The success of the method is greatest when oxytocin is administered in the form of a titration (Turnbull and Anderson, 1968). Karim et al. (1969) successfully induced labour with prostaglandin $F_{2} \alpha$ $\left(\mathrm{PGF}_{2} \alpha\right)$, but if it is to be more widely used in the future $\mathrm{PGF}_{2} \alpha$ must be shown to carry advantages over oxytocin, which is of proved efficiency. One disadvantage of oxytocin is its antidiuretic action (Abdul-Karim and Assali 1961), which may lead to water intoxication (Liggins, 1962). This study shows that administration of $\mathrm{PGF}_{2} \alpha$ has no such complicating effect.

\section{METHODS}

Six patients admitted to hospital for termination of pregnancy by transabdominal intra-amniotic injection of hypertonic saline were studied. In all cases therapeutic abortion had been previously considered necessary on psychiatric grounds. The procedures and risks involved in the experiment were explained to the patients and their full consent and cooperation were obtained. None had any evidence of cardiac, renal, or other disease.

Water diuresis was induced in each by the intravenous 
infusion of $5 \%$ dextrose at a rate of $800 \mathrm{ml}$. per hour. The patients were catheterized (our routine procedure before this method of termination) and the bladder was emptied every 15 minutes. The volume and osmolality of each specimen of urine was measured. After achieving approximate intake-output balance oxytocin (B.P., 20 units $=1$ unit of vasopressin) was administered intravenously by means of a Palmer slow injector to three patients in the dosage shown in Figs. 1-3; with a similar technique $\mathrm{PGF}_{2} \alpha$ was given to the remainder (Figs. 4-6) at a dose rate of $0.05 \mu \mathrm{g} . / \mathrm{kg} . /$ minute, no more than $15 \mathrm{ml}$. being infused in one hour. The doses of both pharmacological agents are within the range which may be used to induce labour at term. The total infusion times of both agents are shown in the figures. The patients were given no medication during the procedures.

Since doses of the two agents are expressed in different terms, it is useful to calculate that $\mathrm{PGF}_{2} \alpha$ given at 0.05 $\mu \mathrm{g} . / \mathrm{kg}$. $/$ minute to a $60-\mathrm{kg}$. woman is $3 \mu \mathrm{g} . /$ minute, which is about equivalent to $6 \mathrm{mU}$. of oxytocin per minute ( 2 units of oxytocin B.P. is contained in $1 \mathrm{mg}$. of substance.)

\section{Results}

Figs. 1, 2, and 3 show that intravenous oxytocin infusion can cause a pronounced antidiuresis in dosage varying from 8 to $128 \mathrm{mU}$./minute. At infusion doses below $128 \mathrm{mU}$./minute the antidiuretic effect seemed to be transient, with recovery occurring during administration at the same level. At a dose rate of $128 \mathrm{mU}$./minute, however, the antidiuretic effect of oxytocin was prolonged, and persisted for four hours after the oxytocin was discontinued, though urine osmolality began to fall after 30 minutes.

Figs. 4 and 5, in contrast, show that there is no antidiuresis during administration of $\mathrm{PGF}_{2} \alpha$ at a rate of 0.05 $\mu \mathrm{g} . / \mathrm{kg} . /$ minute. Fig. 6 shows a slight reduction in urine volume during the first hour after starting $\mathrm{PGF}_{2} \alpha$ administration, but this was due to the patient vomiting shortly before the infusion began. A rebound diuresis is then clearly shown. During $\mathrm{PGF}_{2} \alpha$ administration the smallest urine volume collected was $50 \mathrm{ml} . / 15$ minutes, whereas at an approximate equivalent dose of oxytocin $(8 \mathrm{mU} . /$ minute) collections of 5 $\mathrm{ml}$. or less in 15 minutes were noted.

After stabilization of fluid intake-output the urine osmolality levels in Figs. 4, 5, and 6 remain uniformly low. The highest level was $140 \mathrm{mOsm} . / \mathrm{kg}$. in Case 6 , the patient who vomited during the infusion of $\mathrm{PGF}_{2} \alpha$. This is again in marked contrast to the effect produced by oxytocin. In Case 1 a dose rate of $8 \mathrm{mU}$./minute caused a maximum urine osmolality of $550 \mathrm{mOsm}$. $/ \mathrm{kg}$., and when $128 \mathrm{mU}$./minute was infused a peak of $580 \mathrm{mOsm} . / \mathrm{kg}$. was attained before the infusion was discontinued.

\section{Discussion}

Abdul-Karim and Assali (1961) demonstrated the antidiuretic effect of oxytocin in both pregnant and non-pregnant subjects, and showed that this differed from vasopressin only in respect of dose response and duration of activity. Though Chalmers et al. (1951) and Cross et al. (1960) were unable to find an antidiuretic effect in non-pregnant patients from oxytocin in doses varying from 50 to $700 \mathrm{mU}$./minute it is now accepted that the antidiuretic activity of 20 units of synthetic oxytocin is equivalent to 1 unit of vasopressin (B.P.).

The mechanism by which oxytocin causes antidiuresis is not known. Saunders and Munsick (1966) found that during oxytocin-induced antidiuresis there was no significant reduction in glomerular filtration rate or renal plasma flow and suggested that oxytocin, like vasopressin, increases facultative reabsorption of water from the distal convoluted tubules and collecting ducts.

Little is known about the effect of prostaglandins on water and solute excretion. Herzog et al. (1966) infused $\mathrm{PGE}_{1}, \mathrm{PGE}_{2}$, and $P \mathrm{PA}_{1}$ into the renal artery of dogs and noted an increase in urine volume and free water clearance associated with an increase in homolateral renal flow. These effects of $P_{G E}$ were not reversed by vasopressin. The effect of $\mathrm{PGF}_{2} \alpha$ was not measured. Nakano (1968), working on dogs, noted that $\mathrm{PGF}_{2} \alpha$ caused renal vasconstriction but did not report any effect of this on water and solute excretion. We have shown that $\mathrm{PGF}_{2} \alpha$ in a dose of $0.05 \mu \mathrm{g} . / \mathrm{kg}$. $/$ minute causes no impairment of water excretion during induced water diuresis. If this substance, as seems possible from the results reported by Karim et al. (1969), becomes established as an effective
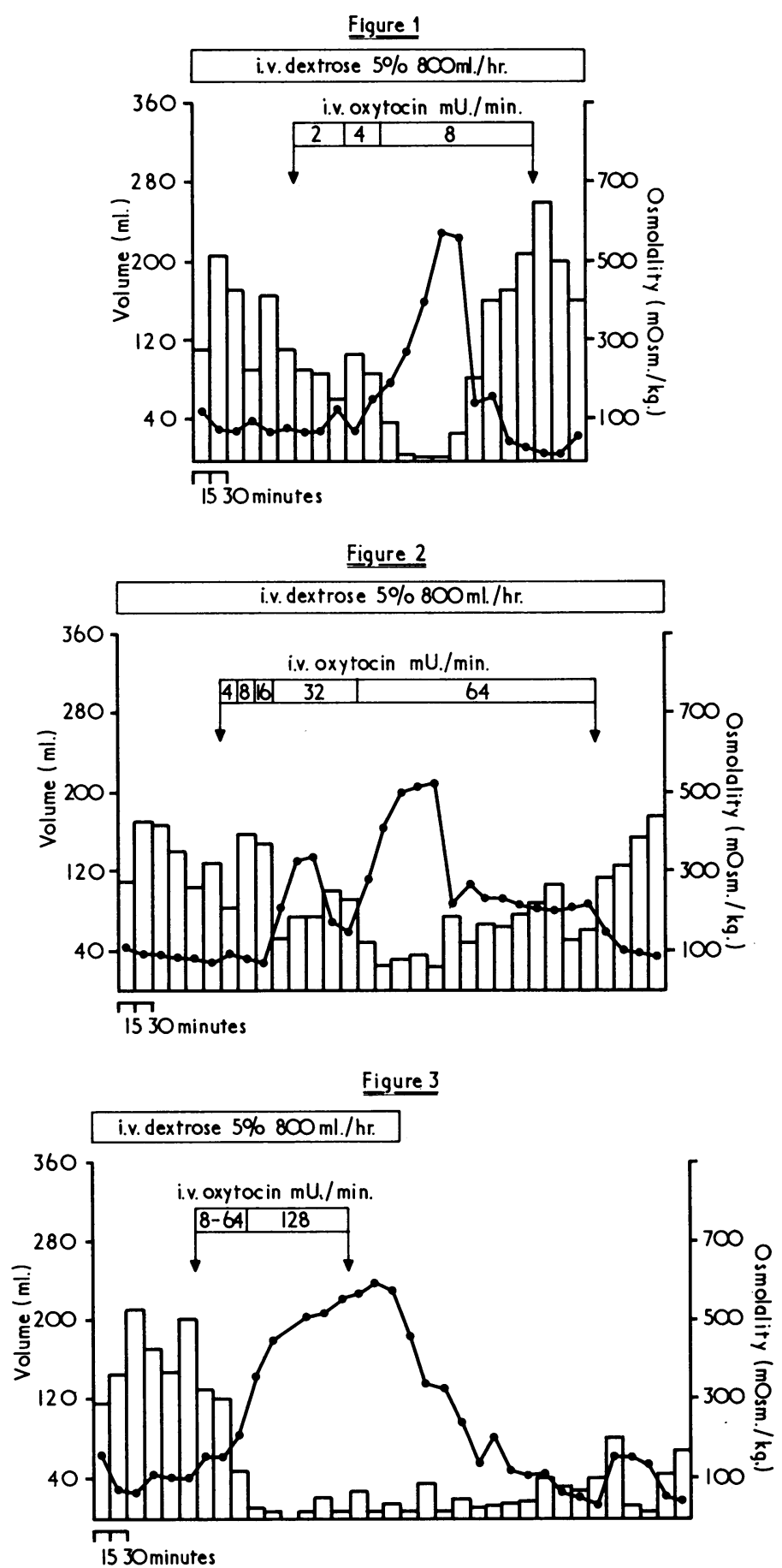

Figs. 1, 2, and 3.-Antidiuretic effects of intravenous oxytocin, infused in doses as shown. The patients werc being given a continuous intravenous water load (see text). The histogram blocks represent 15minute urine volumes in $\mathrm{ml}$. The line tracing represents the trend in urine osmolality in mOsm./kg. 
Figure 4

I.v. dextrose $5 \% 800 \mathrm{ml} / \mathrm{hr}$.
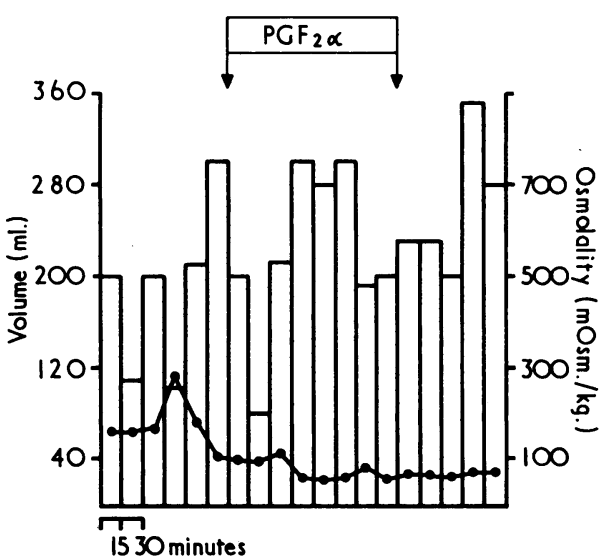

Figure 5

i.v. dextrose $5 \% 800 \mathrm{ml} / \mathrm{hr}$.

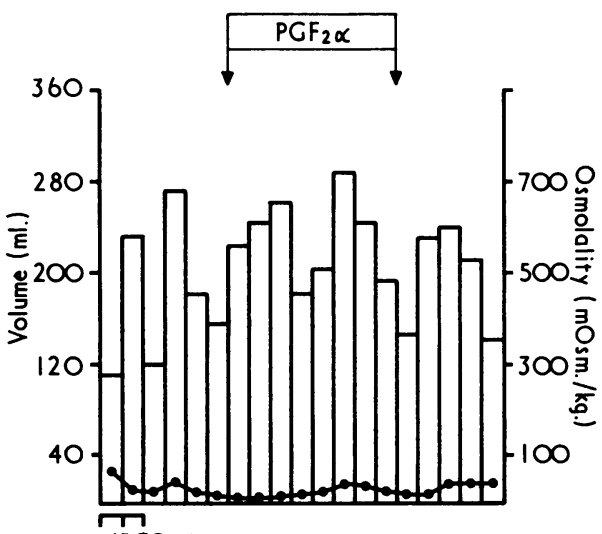

1530 minutes
Figure 6

i.v. dextrose $5 \% 800 \mathrm{ml} . / \mathrm{hr}$.

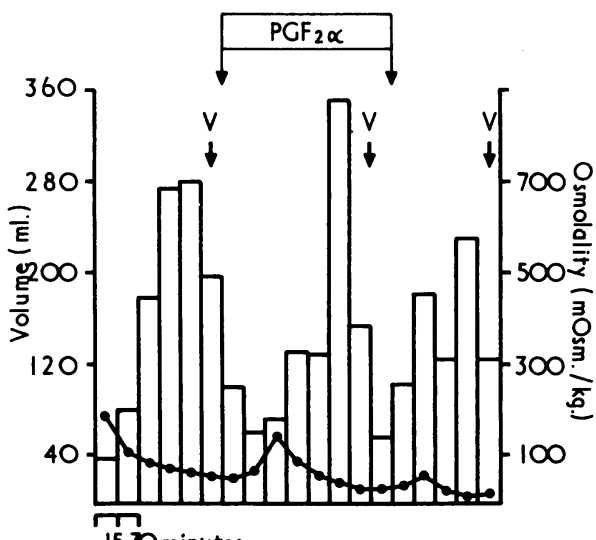

1530 minutes

Figs. 4, 5, and 6.-Lack of antidiuretic effect in response to intravenous PGF $2 \alpha$ infused at $0.05 \mu g$. $/ \mathrm{kg} . / \mathrm{min}$. The patients were being given a continuous intravenous water load (see text). Criteria represented as in Figs. $1-3$. $\mathrm{V}=$ vomited.

pharmacological agent for the induction of labour, the absence of an antidiuretic effect would represent a significant advantage over oxytocin.

The risk of water intoxication with dilute solutions of oxytocin has been reported by Liggins (1962) and by Whalley and Pritchard (1963). If large doses of oxytocin are required to induce labour successfully, then the fluid intake should be limited and the concentration of oxytocin increased rather than the rate of infusion. One of us (G.R.) noted probable water intoxication in a patient who developed an "eclamptic fit" following administration for 14 hours of $3,600 \mathrm{ml}$. of $5 \%$ dextrose containing 8 units of oxytocin per litre. There was no hypertension or albuminuria, and the clinical picture was similar to that described as water intoxication by other workers. Presumably, the risk of such a complication would be much less with $\mathrm{PGF}_{2} \alpha$. It may be of particular value when labour has to be induced because of pre-eclampsia or chronic renal disease, since renal function may be depressed, or in heart disease where plasma volume may be expanded to a dangerous level if an antidiuretic drug is used.

This work was carried out during the tenure of a United Cardiff Hospitals' Research Fellowship to one of us (G.R.). We wish to express our thanks to Professor van Dorp, Vlaardingen, for providing the prostaglandin and to Professor V. R. Pickles for helpful advice.

United Cardiff Hospitals' Research Fellow.

G. ROBERTS, M.B., B.CH., M.R.C.O.G.

Senior Research Fellow.

ANNe ANDERSON, M.D.

Registrar, Obstetrics and Gynaecology

J. MCGARRY, M.B., B.CH., M.R.C.o.G.

Professor, Obstetrics and Gynaecology.

A. C. TURNBULL, M.D., F.R.C.o.G.

Department of Obstetrics and Gynaecology, Welsh National School of Medicine, The Maternity Hospital, Cardiff CF2 1XF.

\section{REFERENCES}

Abdul-Karim, R., and Assali, N. S. (1961). Fournal of Laboratory and Clinical Medicine, 57, 522

Chalmers, T. M., Lewis, A. A. G., and Pawan, G.L.S. (1951). Fournal of Physiology, 112, 238 .

Cross, R. B., Dicker, S. E., Kitchin, A. H., Lloyd, S., and Pickford, M. (1960). Fournal of Physiology, 153, 553 .

Herzog, J., Johnston, H., and Lauler, D. P. (1966). Clinical Research,

Karim, S. M. M., Trussell, R. R., Hillier, K., and Patel, R. C. (1969). fournal of Obstetrics and Gynaecology of the British Commonwealth, 76, 769.
Liggins, G. C. (1962). Fournal of Obstetrics and Gynaecology of the British Commonwealth, 69, 277.

Nakano, J. (1968). Proceedings of the Society for Experimental Biology and Medicine, 127, 1160

Saunders, W. G., and Munsick, R. A. (1966). American fournal of Obstetrics and Gynecology, 95, 5.

Turnbull, A. C., and Anderson, A. B. M. (1968). Fourmal of Obstetrics and Gynaecology of the British Commonwealth, 75, 32.

Whalley, P. J., and Pritchard, J. A. (1963). Fournal of the American Medical Association, 186, 601 .

\section{Medical Memoranda}

\section{Severe Generalized Primary Herpes Treated with Cytarabine}

\section{British Medical fournal, 1970, 2, 154-155}

Cytarabine has been shown to be effective against a number of D.N.A. viruses in cell culture (Underwood, 1962; Underwood et al., 1964), including vaccinia and herpes simplex virus. Kaufman and Maloney (1963) found that cytarabine in a $5 \%$ saline solution was as active as idoxuridine in the treatment of herpetic keratitis in 12 patients.

Toxic side-effects of the drug when given systemically in humans in the treatment of malignant disease in doses of 2-5 mg./kg./day include megaloblastosis and marrow suppression, including leucopenia, anaemia, and thrombocytopenia (Talley and Vaitkevicius, 1963).
Cytarabine has the great virtue of being water soluble, and in view of the favourable results in the treatment of herpetic keratitis and our own favourable though limited experience with the drug used locally in herpetic skin lesions it seemed reasonable to try the effect of cytarabine in a patient in whom a primary infection gave rise to concern.

\section{CASE History}

A 22-year-old male medical student presented on 28 October 1969 complaining of a sore throat and malaise. Apart from recurrent attacks of bronchitis during childhood and early adult life he had had no serious disease. He had never suffered from cold sores. From 22 to 25 October he had daily met and kissed a girl friend, who at that time was "fighting off a cold" and had had "sores on her 